\title{
Bilateral central and centrocaecal scotomata due to mass lesions
}

\author{
ISAAC GUTMAN,* MYLES BEHRENS, AND JEFFREY ODEL* \\ From the Department of Ophthalmology, Columbia-Presbyterian Medical Center, New York, \\ New York 10032
}

SUMMARY Unilateral central or centrocaecal scotoma may result from optic nerve compression. However, such defects bilaterally usually indicate non-compressive optic neuropathy of toxic or nutritional, hereditary, or demyelinating origin. Three cases are reported of patients who presented with somewhat atypical bilateral central or centrocaecal scotomata and were found to have suprasellar mass lesions demonstrated by CT scan and confirmed neurosurgically.

Unilateral central or centrocaecal scotoma may result from optic nerve compression as well as optic neuritis. ${ }^{1}$ Bilateral central or centrocaecal scotomata (which must be distinguished from bitemporal hemianopic scotomata of chiasmal origin) usually indicate optic neuropathy of toxic or nutritional, ${ }^{2}$ hereditary, ${ }^{34}$ or demyelinating origin and have only rarely been associated with mass lesions. We report 3 patients who presented with somewhat atypical

\footnotetext{
${ }^{*}$ Drs Gutman and Odel were Fellows in Neuro-ophthalmology, sponsored by the Nate B. Frances Spingold Foundation, Inc., New York, New York. They are currently at Tel Hashomer Hospital, Tel Aviv, Israel, and Henry Ford Hospital, Detroit, Michigan, respectively.
}

Correspondence to Myles Behrens, MD, 635 West 165th St, New York, NY 10032, USA.

Fig. 1 Case 1. Peripheral visual fields show central scotoma to 16/300 red $O U, 25$ September 1975 (by Dr Frank D. Carroll). bilateral central or centrocaecal scotomata and were found on computed tomography (CT) scan to have a suprasellar mass, confirmed by neurosurgical exploration and pathological examination.

\section{Case report}

CASE 1

A 45-year-old male had noted decreased visual acuity to $20 / 30$ OU in 1970 , with clearing over the subsequent several months. In 1975 there was recurrence, with visual acuity $20 / 30 \mathrm{OU}$ and central scotomata to 16/300 red object only OU (Fig. 1). The discs were minimally pale. Fluorescein angiography was normal. General physical and neurological examinations, cerebrospinal fluid analysis, skull, orbit and optic 


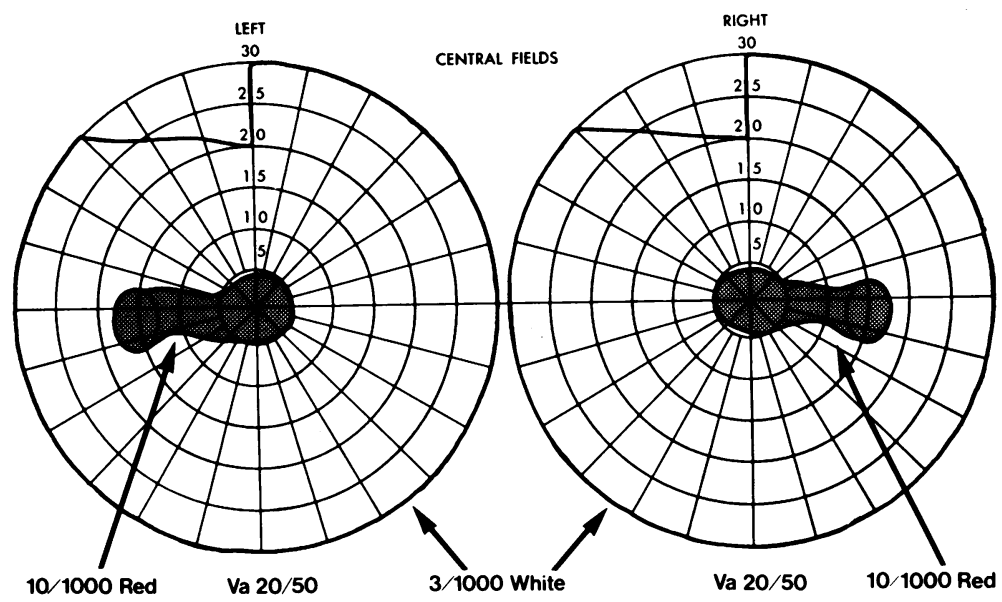

Fig. 2 Case 1. Central visual fields show centrocaecal scotomata to $10 / 1000$ red and left upper homonymous hemianopic defect to 3/1000 white, 8 December 1976.

canal $x$-rays, and brain scan were normal. The visually evoked response (VER) to pattern stimulus showed prolonged latency to $140 \mathrm{~ms} \mathrm{OU}$.

His vision continued to fluctuate, and in December 1976 visual acuity was 20/50 OU. External examination and motility were normal. Four of six HardyRand-Rittler pseudoisochromatic (AOHR) colour plates were interpreted correctly OU. Visual fields showed centrocaecal scotomata to $10 \mathrm{~mm}$ red (not to $3 \mathrm{~mm}$ white) at 1 meter and a left upper homonymous

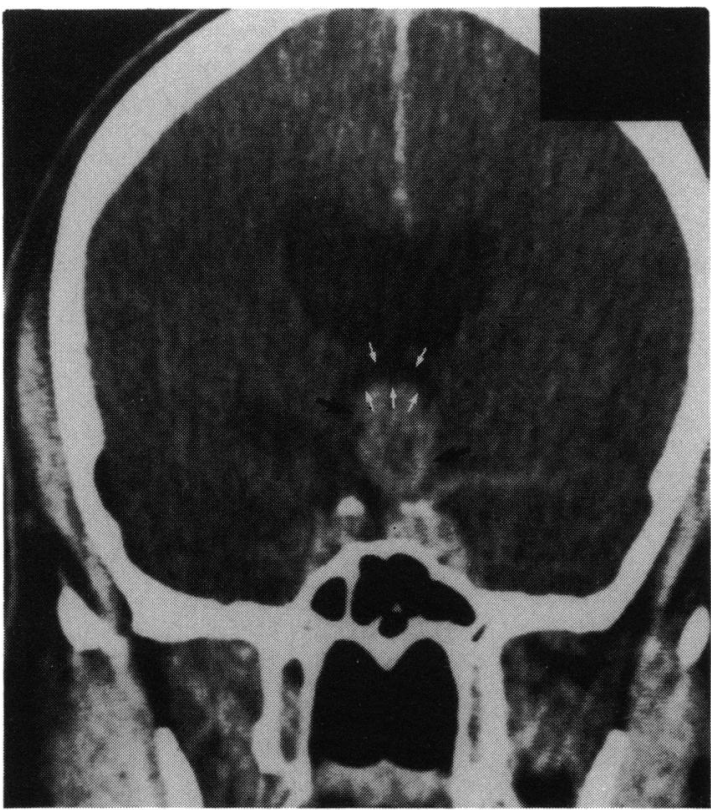

Fig. 3 Case 1. Coronal CT shows a suprasellar enhancing mass (black arrows) with intrasellar invasion. The mass indents the 3 rd ventricle (white arrows) with resulting hydrocephalus. hemianopic defect (Fig. 2). The pupils were sluggish without relative afferent defect, and there was mild temporal disc pallor OU.

Skull and optic canal $x$-rays and optic canal polytomes were normal. CT scan showed a suprasellar mass. At right frontal craniotomy a cystic chiasmal mass was found, presumed a glioma and not biopsied.

The patient was followed up without radiotherapy and did well, with improvement in visual acuity OD to 20/20-1 (OS 20/60). CT scan in March 1979 was unchanged. In May 1979 he complained of severe headache. Papilloedema was found, and CT showed expansion of the tumour, displacement of the third ventricle, and obstruction of the foramen of Monro (Fig. 3). A second craniotomy was done, and a biopsy taken from a chiasmal mass was considered to show cerebral histiocytosis. Radiotherapy was begun. His vision remained unchanged at 31 March 1981.

CASE 2

A 31-year-old male had noted painless central blurring of vision with dyschromatopsia OS since March 1979 , fluctuating clearly in response to prednisone. In June 1979 he developed a similar but less severe involvement OD. CT scan was negative without high resolution orbital views. In July 1979 bilateral central scotomata were found (Fig. 4) to 2/1000 white OD and 10/1000 white OS, with visual acuity 20/20 OD, 20/200 OS, with mild general depression of field (5 white not seen OS).

In August 1979 visual acuity was 20/20-1 OD and 20-70 OS. External examination and motility were normal. AOHR colour plates were interpreted correctly $2 \frac{1}{2}$ of 6 OD and none OS. Visual fields showed temporal nonhemianopic paracentral relative scotoma to $10 / 1000$ red OD and centrocaecal scotoma OS to $3 / 1000$ white and relative to $10 / 1000$ red (Fig. 5). There was a mild relative afferent pupillary defect 
OS. There was mild left and questionable right disc pallor. General physical and neurological examinations were negative, as were complete blood count, erythrocyte sedimentation rate, lupus erythematosus cell test, and cerebrospinal fluid analysis. VER indicated left optic neuropathy.
Fig. 4 Case 2. Bilateral central scotomata to 2/1000 white $O D$ and 10/1000 white OS, July 1979 (by Dr Thomas Kuhns).

Fig. 5 Case 2. Temporal nonhemianopic paracentral scotoma to $10 / 1000$ red $O D$ and centrocaecal scotomata to $3 / 1000$ white and 10/1000 red OS, 23 August 1979.
Fig. 6 Case 2. Bitemporal hemianopic scotomata with scotomatous nasal central depression OS, 18 September 1979.
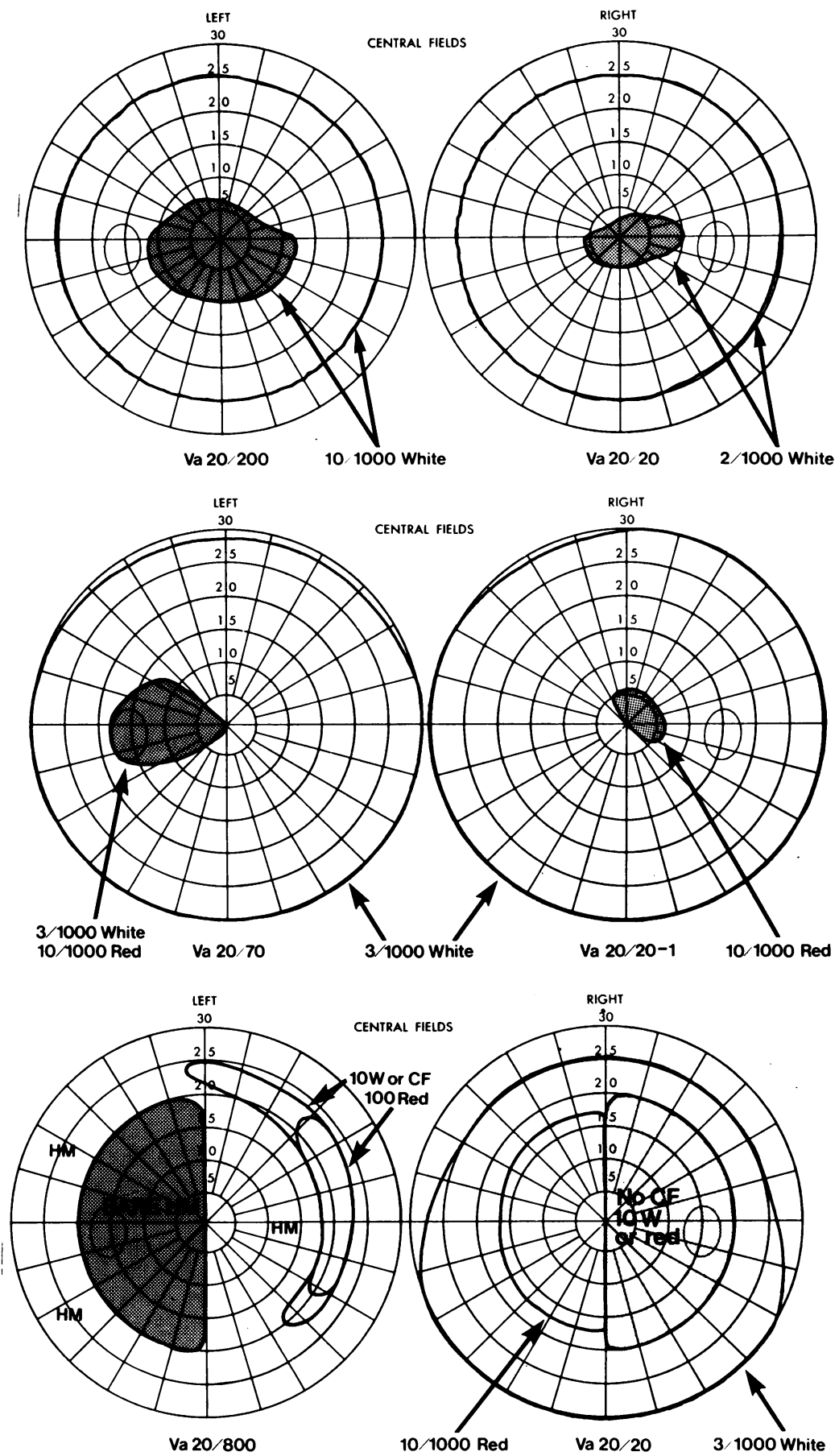
After tapering of the prednisone his vision worsened, and one month later his visual acuity was 20/20 OD, 20/800 OS, with bitemporal hemianopic scotoma and scotomatous nasal central depression as well OS. (Fig. 6). CT scan showed a suprasellar mass

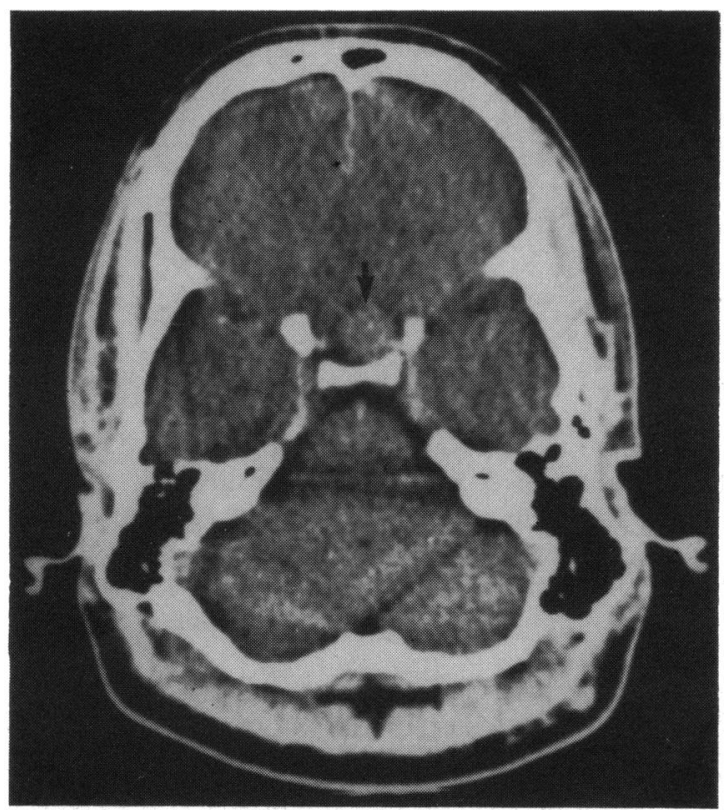

Fig. 7A

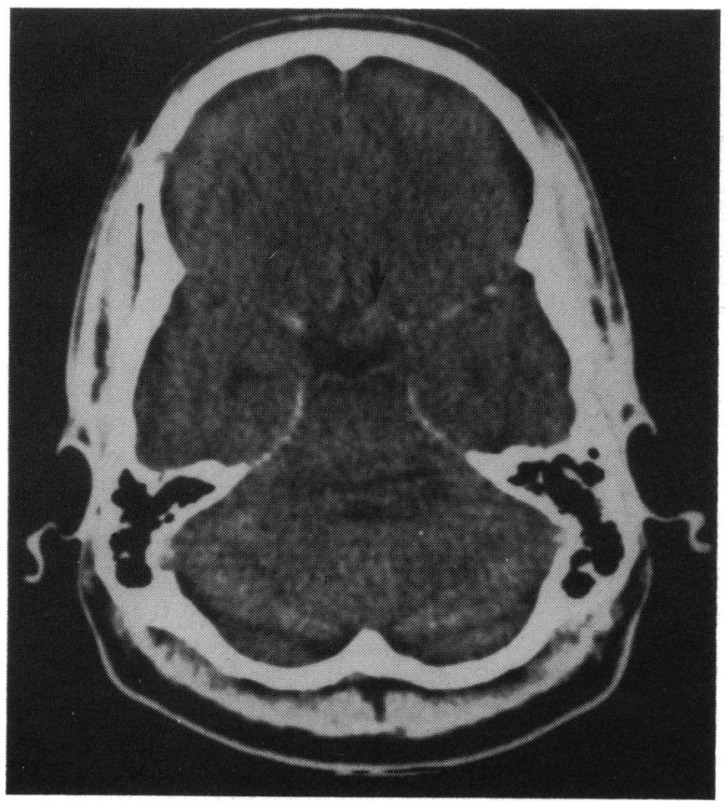

Figs. 7A, B Case 2. Axial CT shows widening of the interclinoid space with intra- $(7 A)$ supra- $(7 B)$ sellar enhancing mass (black arrows).
(Fig. 7A and 7B). At craniotomy there was a 'large mass in the suprasellar area between the optic nerves, touching both optic nerves and most likely originating in the optic chiasm . . . grossly a typical glioma . . . grayish in color with vascularity resembling nerves over it.'Biopsy confirmed optic glioma. Radiotherapy was started. He was not followed up.

\section{CASE 3}

A 22-year-old male had noted fluctuating progressive visual blurring over 2 months since September 1981. On 13 November visual acuity was 20/25-1 (slowly) OD and 20/50-2 OS. External examination and motility were normal. The visual fields showed generalised constriction with bilateral centrocaecal scotomata to $3 / 1000$ white, relative to $10 / 1000$ red (Fig. 8). AOHR colour plates were interpreted correctly 0 of $6 \mathrm{OU}$. The pupils were slightly sluggish with a possible right relative afferent defect. The posterior poles were normal. General physical and neurological examinations were otherwise unremarkable.

The complete blood count, ESR, antinuclear antibody test, serology, and vitamin $B_{12}$ levels were all within normal limits. $X$-rays of skull and optic canals were normal. CT scan showed a suprasellar mass (Figs. 9, 10). At craniotomy a cystic craniopharyngioma was found (Fig. 11) and drained. Four days later visual acuity was 20/20 OU, with normal visual fields.

\section{Discussion}

These 3 patients presented initially with somewhat atypical bilateral central or centrocaecal scotomata. There was no history suggestive of non-compressive bilateral optic neuropathy of toxic or nutritional, ${ }^{2}$ hereditary, ${ }^{34}$ or demyelinating origin, and suprasellar mass lesions were demonstrated (intrinsic in cases 1 and 2 and extrinsic in case 3 ). Such bilateral central or centrocaecal scotomata (which must be distinguished from bitemporal hemianopic scotomata) have only rarely been reported in patients with mass lesions. In 1923 in his Bowman lecture de Schweinitz ${ }^{5}$ reviewed past studies of visual field defects occurring with pituitary tumours. He mentioned only one report of bilateral centrocaecal scotomata by Lohman (p. 39). In 1939 Henderson ${ }^{6}$ reviewed the visual field changes in 243 patients operated on by Cushing for pituitary adenoma. In 6 cases bilateral central scotomata were recorded but only diagrammatically represented. Hirsh and Hamlin ${ }^{7}$ reported central scotomata in $11 \%$ of 59 cases with pituitary tumours without giving further details of the visual field defect and probably unilateral. Hollenhorst and Younge ${ }^{8}$ in an analysis of 1000 cases of pituitary adenoma did not record 
Fig. 8 Case 3. Bilateral

centrocaecal scotomata to $3 / 1000$ white, relative to $10 / 1000$ red, with peripheral depression, 3 November 1981.

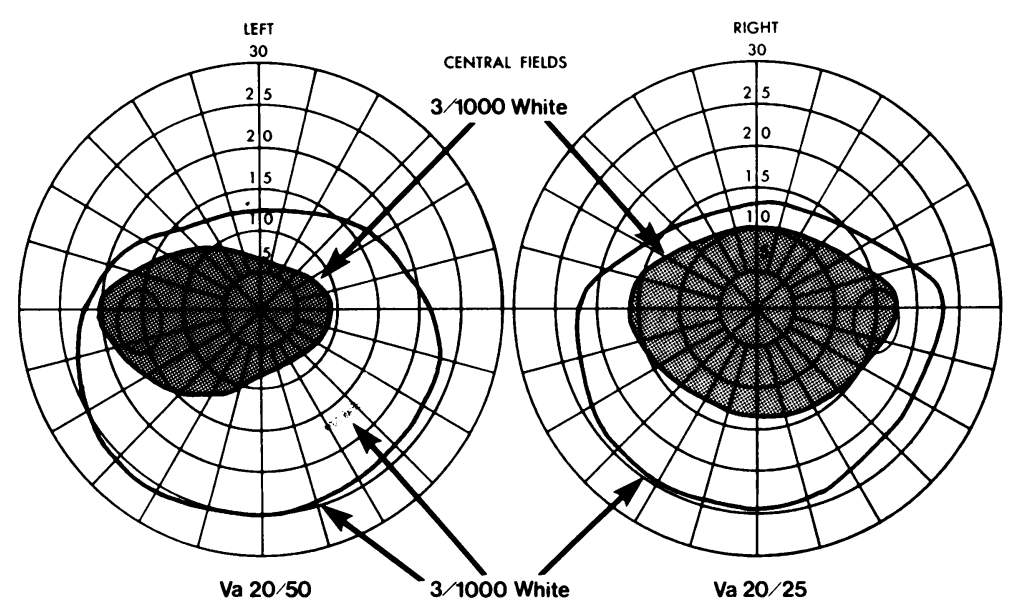

bilateral central or centrocaecal scotomata, although such cases may have been included in 27 cases with central or temporal scotoma (both eyes).'

Single cases of bilateral centrocaecal scotomata due to mass lesions were reported by Kelly ${ }^{9}$ (his Fig. 7), Nettleship ${ }^{10}$ (his Figs. 49, 50), Schlezinger et al. ${ }^{11}$

(their Fig. 6, with irregular shape), Lloyd ${ }^{12}$ (pp. $177-8$, where smoking was a possible factor and bitemporal hemianopia supervened with pituitary disease 3 years later), and mst recently Kline ${ }^{13}$ (his Fig. 1, with constriction of peripheral isoptres as well, with the finding at surgery of compression by a

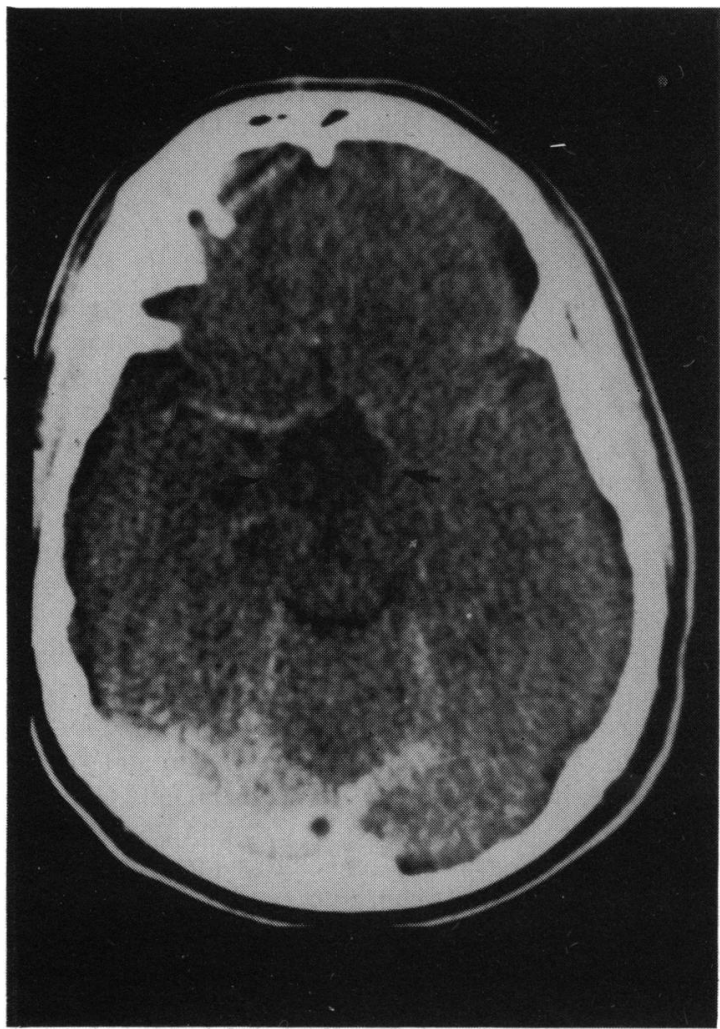

Fig. 9 Case 3. Axial CT shows the suprasellar cistern enlarged and deformed by a low density mass (black arrows).

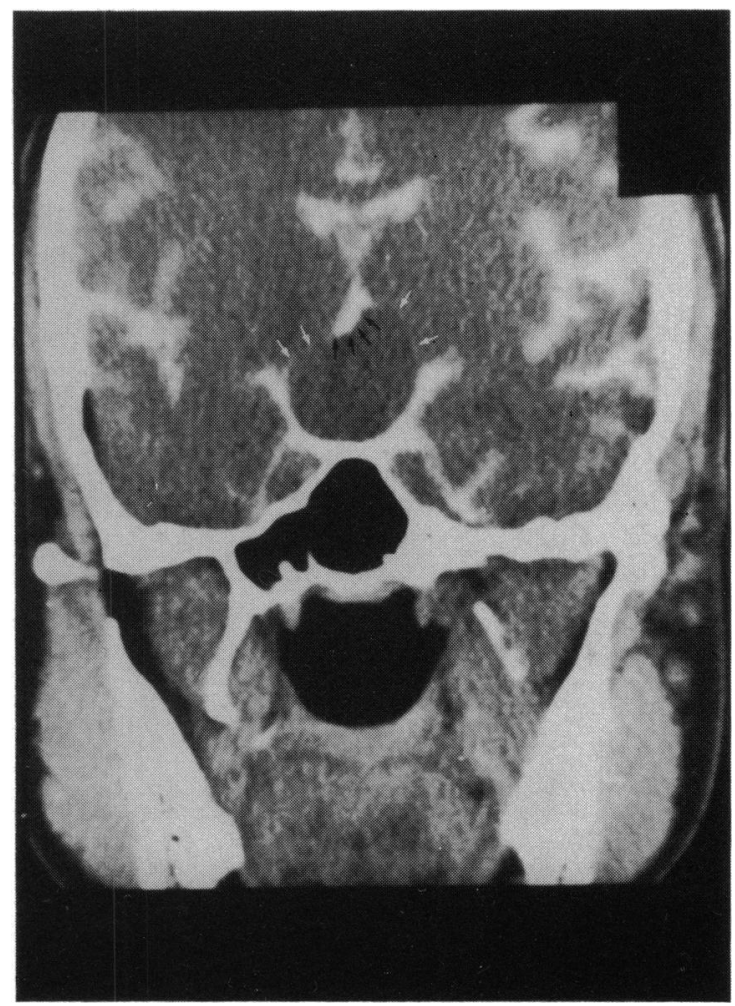

Fig. 10 Case 3. Coronal CT with metrizamide shows deformity of the lower part of the 3rd ventricle (black arrows) by a suprasellar mass (white arrows). 


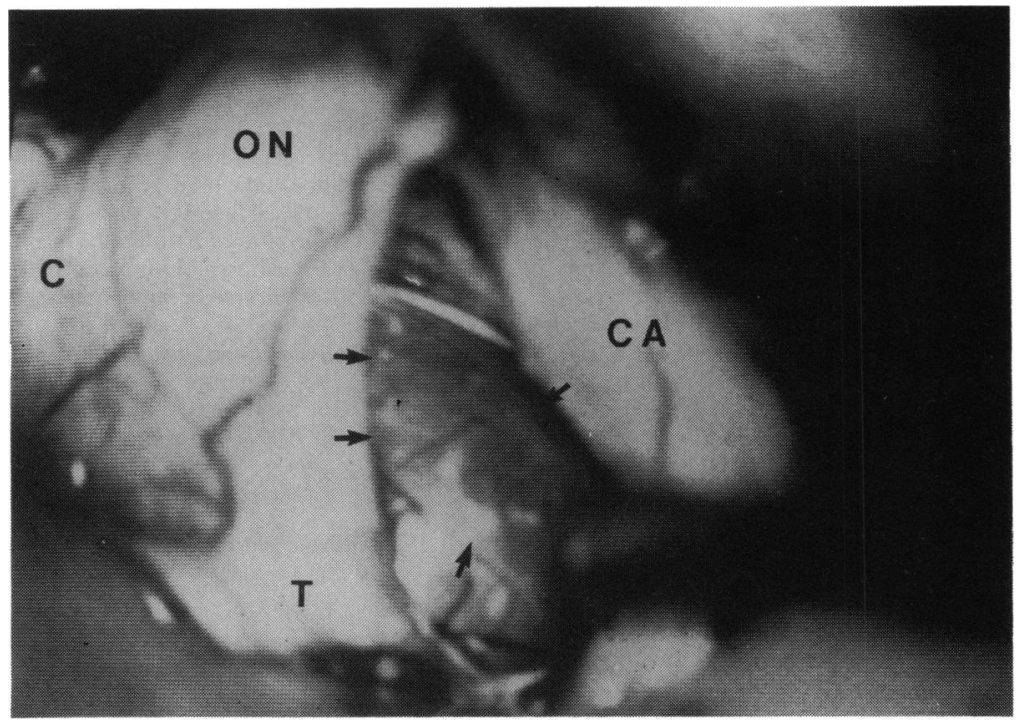

Fig. 11 Case 3. Operative photograph shows the right optic nerve $(O N)$, chiasm $(C)$, and tract $(T)$ with the internal carotid artery (CA) retracted to expose a cystic mass (black arrows). thrombosed aneurysm of both optic nerves and the anterior chiasm, which was postfixed). Walsh ${ }^{14}$ recorded one case of bilateral central scotomata, described as denser on the temporal side. Kelly ${ }^{9}$ also recorded a case of bilateral central scotomata without illustration patient (E.C., pp. 152-4).

Sugita et al. ${ }^{15}$ found 8 of 46 cases of pituitary adenoma to have central scotomatous defect, though not pure bilateral centrocaecal scotomata. In one case (their case 2) bilateral central scotomata were reported (though the visual fields were not shown) and attributed to elevation of both optic nerves by the tumour at surgery. They discussed the mechanism for such central scotomatous defects of compressive origin, implicating involvement of the papillomacular fibres by bilateral optic nerve compression in some cases and chiasm compression, as is clearly the mechanism of bitemporal hemianopic scotomata, in others. In our second case such hemianopic scotomata were noted in evolution of the visual field defect after centrocaecal scotomata were recorded.

A combination of such central non-hemianopic visual field defects with depression of the peripheral visual field occurs, ${ }^{1113}$ in some cases hemianopic. Thus Sugita et al. ${ }^{15}$ recorded a case (5) with pericaecal, nearly centrocaecal, scotomata with bitemporal hemianopic quadrantic defect. Some peripheral visual field depression or defect developed in each of our cases, and hemianopic defect eventually developed in our cases 1 and 2. Analogously Feldon ${ }^{16}$ recently emphasised the finding on computerised automated (Octopus) perimetry of non-hemianopic arcuate defects in addition to more prominent bitemporal visual field defects in patients with chiasm compression by pituitary adenoma.
As in the 3 cases reported here, it would appear that one must consider intracranial mass lesion(s) as a cause of not only unilateral but also occasionally bilateral central or centrocaecal scotoma. Such an aetiology should be considered in the absence of a history suggesting a toxic or nutritional or hereditary basis or other indication of demyelinating disease. Other atypical features prompting such consideration include a relentlessly progressive course, unusual pattern of scotomata, peripheral visual field depression, especially if hemianopic, or steroid responsiveness, ${ }^{17}{ }^{18}$ as suggested in our second case. Little or no disc pallor is characteristic of early optic nerve or chiasm compression and does not militate against its consideration or appropriate investigation. ${ }^{19} \mathrm{~A}$ high resolution $\mathrm{CT}$ scan should be obtained in such cases of unexplained or atypical central or centrocaecal visual field defects.

We are grateful to Dr Frank D. Carroll for advice and support.

\section{References}

1 Trobe JD, Glaser JS. Quantitative perimetry in compressive optic neuropathy and optic neuritis. Arch Ophthalmol 1978; 96: 1210-6.

2 Carroll FD. Analysis of 55 cases of tobacco-alcohol amblyopia. Arch Ophthalmol 1935; 14: 421-34.

3 Anonymous. Leber's optic neuropathy. Br Med J 1980; 280: 1097-8.

4 Kline LB, Glaser JS. Dominant optic atrophy. Arch Ophthalmol 1979; 97: 1680-6.

5 DeSchweinitz GE. Bowman lecture, 1923. Trans Ophthalmol Soc UK 1923; 43: 12-109.

6 Henderson WR. The pituitary adenomata: a follow-up study of the surgical results in 338 cases (Dr. Harvey Cushing's series). $\mathrm{Br}$ J Surg 1939; 26: 811-79. 
7 Hirsh O, Hamlin H. Fate of visual field and optic discs in pituitary tumors. Am J Ophthalmol 1954; 37: 880-3.

8 Hollenhorst RW, Younge BR. Ocular manifestations produced by adenomas of the pituitary gland: analysis of 1000 cases. In: Kohler PO, Roses GT, eds. Diagnosis and treatment of pituitary tumors. Amsterdam: Excerpta Medica, 1973: 53-68.

9 Kelly R. Lesions of the optic chiasm due to compression. Trans Ophthalmol Soc UK 1962; 82: 149-64.

10 Nettleship E. Central amblyopia as an early symptom in tumour of the chiasma. Trans Ophthalmol Soc UK 1897; 17: 277-99.

11 Schlezinger NS, Alpers BJ, Weiss BP. Suprasellar meningiomas associated with scotomatous field defects. Arch Ophthalmol 1946; 35: 624-42.

12 Lloyd RI. Visual field studies. New York: Technical Press, 1926.

13 Kline LB. Chiasmal compression without bitemporal hemianopia. In: Smith JL, ed. Neuro-ophthalmology focus 1982. New York: Masson, 1982, 223-30.
14 Walsh FB. Clinical neuro-ophthalmology. 2nd ed. Baltimore: Williams and Wilkins, 1957: 1014-6.

15 Sugita K, Sato O, Hirota T, Tsugane R, Kageyama N. Scotomatous defects in the central visual fields in pituitary adenomas. Neurochirurgia (Stuttg) 1975; 18: 155-62.

16 Feldon SE. Octopus ${ }^{\mathrm{TM}}$ quantitative perimetry in the evaluation of chiasmal field defects. Presentation at the Frank Walsh Society Meeting, Los Angeles, California, 19-20 February 1982.

17 Lessell S. Comment: Is there a place for corticosteroids in the management of optic neuritis? In: Brockhurst RJ, Boruchoff SA, Hutchinson BT, Lessell S, eds. Controversy in ophthalmology. Philadelphia: Saunders, 1977: 839-840.

18 Perkin GD, Rose FC. Optic neuritis and its differential diagnosis. Oxford: Oxford University Press, 1979: chapter 5.

19 Knight CL, Hoyt WF, Wilson CB. Syndrome of incipient prechiasmal optic nerve compression. Arch Ophthalmol 1972; 87: $1-11$. 